\title{
Existential needs of people with psychotic disorders in Pôrto Alegre, Brazil
}

\author{
LUCIANE C. WAGNER and MICHAEL KING
}

\begin{abstract}
Background Needs for care in service users with schizophrenia are often defined by professionals and focus on basic needs for health and social care rather than broader existential issues.
\end{abstract}

Aims To examine the perceptions of users and formal and informal carers of the needs of people with non-affective psychosis.

Method A qualitative study was conducted involving focus groups of service users and informal and formal carers in a major Brazilian city.

Results Existential needs were the most important theme for people with psychotic disorders. Informal and formal carers mainly regarded such needs as secondary to needs for health, housing, leisure and work. Carers usually reduced the existential questioning of the ill person to symptoms or the result of a privation such as lack or failure of medication and its consequences.

Conclusions We require an approach to service users wherein respect and understanding are prized as the first needs from which all others will naturally follow. We also need to give greater priority to existential issues in validated schedules that measure needs in clinical work and research.

Declaration of interest None.
A number of instruments have been developed to identify the needs of people with psychiatric disorders: for example, the Medical Research Council's Needs for Care Assessment (Brewin et al, 1987; Brugha et al, 1988) and the Camberwell Assessment of Needs (Phelan et al, 1995). These scales were developed by agreement between professionals, and lack the perspective of service users and informal carers who live every day with the consequences of these disorders. Possibly as a result, these scales emphasise needs for social and healthcare, contacts with services, accommodation and employment. Our aim was to use qualitative methods to examine the perceptions of service users and of formal and informal carers of the needs of people with psychotic disorders. In doing so, we found that many expressed needs could not be categorised into the domains of social well-being or health; rather, they concerned the suffering of the individuals affected and their fears, questioning and search for meaning. These can be regarded as 'existential', as they concern a need for meaning and values in what is often assumed to be a meaningless universe. The data arise out of a larger, cross-national investigation of psychiatric service users' needs for formal and informal care as well as their experiences of stigma in Brazil, Argentina, Chile, Venezuela, Spain and England. The data presented here concern only the findings on existential needs in the population studied in Pôrto Alegre, southern Brazil.

\section{METHOD}

Understanding the complex needs of people with a psychotic disorder requires a qualitative approach in which meanings, stereotypes and prejudice can be assessed with precision and reliability (Britten, 1995). We used focus groups to provide data that were not limited by our preconceptions of what we as mental health professionals would find (March Cerdà et al, 1999; Bauer \& Gaskell, 2000).

\section{Participants}

We recruited three samples:

(a) a purposive sample of people with schizophrenia and other psychotic disorders defined according to ICD-10 (World Health Organization, 1992); this sample contained a balance of men and women, with a wide age range over 15 years; a duration of illness of 3-15 years; psychiatric hospitalisation for no more than $40 \%$ of the preceding 3 years and no more than 3 months continuously in the preceding year; and a fluency in the national language, Portuguese;

(b) informal carers: people who lived with, or were very close to, someone with a psychotic illness, were recognised as main providers of informal care and had no contract with mental health or other services;

(c) formal carers: mental health professionals who had at least 3 years' experience working with individuals with psychoses.

\section{Focus groups}

In March 2002 we conducted four focus group sessions with people with psychotic disorders, two with informal carers and two with mental health professionals. Each group contained six to eight participants. Of those approached, 24 of 35 people with psychotic disorders, 16 of 28 informal carers and 17 of 20 professionals agreed to participate. We recruited participants from mental health and primary care services, as well as from associations for people with schizophrenia.

\section{Conduct of the focus groups}

Each group was facilitated by a psychiatrist who held a checklist of themes as a guide to the group discussion.

(a) What are the needs (in all domains of life) of people affected by psychotic disorders?

(b) Has the illness provoked changes in people's needs, and if so, what are they?

(c) Do people with psychotic disorders need more or different kinds of care? If so, what kind of care and who should offer it? 
(d) Do people with psychoses suffer stigma or discrimination? If so, in what ways and to what extent?

(e) How could the lives of people with these illnesses be improved?

An observer assisted the facilitator, made notes and operated the tape recorder. The meetings lasted an average of $90 \mathrm{~min}$ and took place in a comfortable and neutral environment distant from mental health services. The audiotape recordings of the group were transcribed.

\section{Coding, analysis and interpretation of the data}

After full discussion and review of the literature on people's needs for care and stigma related to psychotic disorders, we defined a tree of categories. After reading the transcripts several times, we found the initial tree was insufficient to cover all the information arising from the transcripts. New categories emerged during this inductive process, most of which concerned existential needs. A further coding process was then started, in which all the text segments coded as existential needs were considered in detail again, in order to refine and classify them into sub-categories. We then undertook a content analysis of the transcripts in order to produce an objective and systematic description of the participants' speech (Bauer \& Gaskell, 2000; Gil-García et al, 2002). To increase the reliability of the coding and analysis, segments of the transcripts were coded individually by the investigators, using the tree of categories elaborated, and compared later. Discrepancies in coding were discussed and resolved by consensus. Coded data were organised using QSR NUD*IST 4, a computer software package for qualitative data (Gil-García et al, 2002). Only data on existential needs are reported here.

\section{RESULTS}

Existential needs were the most important and pressing theme for people with psychotic disorders. However, their questioning was often very personal, difficult to verbalise and linked to beliefs about existence and the meaning of their illness and their lives. Informal and formal carers mainly regarded such needs as secondary to needs for health, housing, leisure and work. Carers usually reduced the existential questioning of the ill person to symptoms or the result of a privation such as lack or failure of medication and its consequences.

\section{Need for personal development}

These issues concerned needs for a task in life, not in the concrete sense of providing an occupation to fill the day but rather in the context of motivation, ability and self-respect. Although loss of motivation frequently arose as an issue, carers associated it with service users' lack of interest and concentration. Service users felt they could not work or study because they were 'moored' and 'motionless'. Many felt they had regressed in their life course and perceived the illness as a malign obstacle to their personal development:

"This illness delayed me. . . I am thirty years old and many things I wanted to carry through I did not obtain because of the illness. . I would like to work, to have a career, to be independent' (E., 29-year-old service user).

Hallucinations and other symptoms disturbed their performance and they took more time to initiate and to finish tasks, no longer played the same part in life, felt useless and sometimes wished to die. Some were tormented by doubts that they were competent enough to accomplish ordinary tasks. They feared facing difficulties and lacked the initiative to react to the problems of life. Feeling diminished, they were unable to support themselves financially. Some believed this came about because their informal carers did not trust their capacity. This frustration most clearly emerged in their beliefs that all the friends of their youth had careers, partners and children, whereas they were arrested in time and had accomplished nothing useful. They would have liked to have had a professional identity, but many complained they did not have enough energy to support the same workload as the others:



'I would like to have a good wage, a house, children . . . but l'm always tired, without disposition to work . . . if I didn't have this illness, I could be a doctor' (C., 30 -year-old service user).

Not all service users, however, were despairing. They talked about the importance of being useful and taking responsibility as a way of gaining respect from others and feeling worthy. A number talked of the importance to keep fighting and the need to survive, despite the disorder and its limitations. In contrast, many carers spoke of patients' lack of a sense of reality and that their ambitions often ran beyond their capabilities. They regarded them as lacking concrete objectives and having difficulty in finding meaning for their existence:

'He has will, plans to retake his life, but he doesn't
know how to do that' (M., 56 -year-old informal
carer).

Some commented on concrete needs such as the chance to work in a tolerant, protective and stimulating environment, without recognising that for many service users this was regarded as patronising.

\section{Need for integrity of the self}

Many service users were shaken at the unexpected nature of their illness and felt that their brains were now disorganised, which generated a fear of losing self-control, becoming 'crazy' and attacking others. They described their brains as 'blocked' and as if everything had disappeared. Many reported feeling lost in time and space. These sensations were connected to hopelessness, depression and a wish to die:



'I've lost concentration. . . it seems I'm floating, my mind is becoming vacant, empty. This scares me' (A., 29-year-old service user).

Many service users perceived the illness as a concrete thing, distinct from their being. Something bad and inexplicable had occurred within their bodies that needed to be extirpated but they did not know how. Some had difficulty understanding the meaning of their thoughts and the views of people around them; as a result, they refrained from saying what they thought because of a fear of offending or seeming inadequate.

Many service users spoke of the intense suffering that resulted from the feeling that their physical and emotional integrity was under constant threat. Some complained that their family and doctors appeared not to understand and interpreted everything as a symptom. They felt they had no escape and no one to whom they might appeal. Everything was regarded by others as madness and not as a genuine threat to their sense of identity and humanness:

'They always find that I am sick, they don't value me as a person, but as a patient' (E., 30-yearold service user). 


\section{Need to win respect and avoid shame}

The majority of service users had experienced the anguish of discrimination, which had made them seek to be invisible. However, they also craved respect and a desire not to be stigmatised. They were aware that prejudice arose internally when they judged themselves as useless, incapable or insane. They wanted to be accepted and understood as they were. Almost all were reluctant to discuss having schizophrenia, for fear of being seen as 'wild' and being rejected. They frequently believed that people around them held very negative images of schizophrenia and regarded people with this disorder as subject to aggressive and uncontrolled impulses. Thus, many feared losing their autonomy and human rights. Some believed that people actively desired their disgrace. Others simply felt they were a nuisance to others:

'I feel myself rejected, banished... by my parents...my sister is the only one who understands me.' (J.-F., 42-year-old service user).

Many had encountered difficulties finding work, or had been dismissed and lost all their rights as workers when the psychosis began. This generated discouragement and a lack of will to continue. As a result, some preferred to withdraw from social contact. They had become confused about what to do and how to proceed. They felt ashamed and diminished. Some commented on the need to control their sense of shame and anger and respond appropriately when they were discriminated against:

'I was called insane many times... and I had a paranoia about catching and beating these people . . but God didn't want that and I controlled myself' (D., 28-year-old service user).

On the other hand, many expressed the need to find positive ways of dealing with prejudice. Continuing their struggle against intolerance was regarded as a fundamental response to their illness. Others stressed that not everybody rejected them. They highlighted the importance of their family and professionals as agents of change, who promoted tolerance and gave greater support. Several had rediscovered a reason for living in group therapy, where they found friends with whom they could share their joys and sufferings and feel accepted and comforted.

\section{Need for autonomy}

The gap between their need for independence and the difficulty of achieving it was one of the most important conflicts for people with psychotic disorders. Many wanted to be free to take decisions, to go and to come as they pleased and be able to take care of themselves. However, their illness limited their capacity for autonomy and led to feelings of dependency and weakness. Although they recognised that their informal carers supported and encouraged their daytime activities, they also believed that carers reduced their autonomy by assuming that they were limited and by lacking trust in their capacity. Many complained that they lacked privacy and felt 'invaded' by the observations of others, who did not respect their decisions or choices. This generated the sensation of being 'anchored', imprisoned and permanently watched by the family.

\section{Need for love}

Many patients reported difficulty expressing feelings and that their illness and its treatment had reduced their ability to relate to others as friends or sexual partners. When the disorder began, friends, family and partners had often grown more distant, causing great suffering. Many patients expressed a need to marry and have their own family and children. However they often perceived others as indifferent or averse to them and that 'nobody wanted to have a relationship with a schizophrenic'. The majority of patients taking part in the focus groups were single and lived with their parents. Many appeared to have better relationships with strangers than with their informal carers. They expressed ambivalent emotions towards their families and had difficulty accepting limits on their own behaviour, as well as the subsequent guilt and sadness when things went wrong. They dreaded losing the support of those on whom they most depended when they were verbally or physically aggressive. Many feared becoming more lonely and isolated if their informal carer died or moved away. On the other hand, some would have liked to live alone and not with their family, with whom they did not have a good relationship. They believed that their family's expectation that they would be aggressive actually provoked their violent behaviour. Although many regarded the support of family and friends as a reason to continue living and facing their disorder, they felt criticised and subject to continuously negative evaluation.

\section{Need for acceptance and understanding of the psychosis}

Accepting their illness, regardless of whether it had any 'meaning', was an important existential need. Many people with psychotic disorder had experienced revulsion and dismay when they discovered that they had the disorder, and many did not accept the diagnosis:

'That destroyed me and I thought "no! I don't have this... I'm not going to take this treatment".' (D., 28-year-old service user).

Others talked of their anger with their doctors who they believed had provided insufficient information or who for a considerable time had spoken only of 'a problem of the nerves'. Although for some patients unfamiliarity with (or delayed recognition of) the illness was associated with denial and a means of escaping the truth, many also felt that adequate information on the nature of schizophrenia helped them question their symptoms, challenge them and progress. Group therapy, in which they had exchanged experiences with other people with the same problem, had increased their understanding of the illness, made it possible to accept it and increased their self-esteem. Some patients commented on the need to search out information on schizophrenia for themselves, instead of waiting for it to be provided. They wanted to reflect on themselves and what had happened since the disease began. They recognised a need to learn to live with the illness, to recognise they had limitations, but also that they were capable of achieving much in life:

'Since I started to search information on my disease, listen to the radio and read in the papers about it, I've reacted better' (L., 4I-year-old service user).

Some commented that every person has their 'time' and that self-acceptance can take much time. Unfortunately, however, many also commented on their desperation that, despite having received treatment and knowing all about their illness, they kept feeling that people rejected them and treated them harshly.

\section{Need for spirituality}

A small number of service users - and no carers - talked about a need for faith. By that, they meant that they hoped that God would help doctors to find a cure for the disorder, help their family and improve their life. They spoke of the need to forget 
the bad experiences of the past and to face the illness with faith in a better future.

\section{DISCUSSION}

Our main finding is that existential needs were of greatest concern to service users. These needs dominated every conversation, even those relating to more everyday concerns. Whereas carers were preoccupied by needs for care and treatment, patients were most concerned by the need for autonomy, self-respect and the avoidance of discrimination.

\section{Limitations}

The study involved service users from one country only and was restricted to those who were able to express themselves. It is possible to regard some of what we call 'existential needs' as manifestations of schizophrenia's negative symptoms, which reduce an individual's capacity for investment in daily tasks and limit the possibility of personal development. However, in so doing we are in danger of making the same reductionist interpretation as their informal and formal carers. Improved medical treatments for these symptoms help service users to achieve a meaningful existence and diminish the criticism of those closest to them, but this does not reduce the reality, complexity or meaning of these existential needs.

\section{Existential needs and personal development}

In his theory of human development, Maslow (1954) described 'higher' human needs for personal growth. At the lower level of a presumed hierarchy, so-called basic needs for safety, food and shelter required fulfilment before higher levels concerning effective social interactions and a sense of meaning and self-worth. However, our data revealed exactly the opposite. Although often materially impoverished and lacking in basic needs, the overriding issue for patients was dissatisfaction with their existence and a lack of meaning. Needs for personal development, autonomy, acceptance and respect, love and identity dominated the discussion in all service user groups. Frankl (1979) has also highlighted this objection to Maslow's theory, arguing that when the lowest needs are not satisfied, the desire for meaning can become the most urgent need of all. These transcripts suggested that, even in the face of serious financial and health difficulties, service users had found the courage to face their illness when the love of family and friends gave them reason to keep living. Schizophrenia appears to have a worse prognosis in high-income countries (World Health Organization, 1973; Jablensky et al, 1992; Leff et al, 1992), despite better standards of living and provision of health services. Explanations for this difference have been found in socio-cultural differences between countries, such as greater social tolerance and lesser competitiveness in low-income countries. On the other hand, alternative resources such as protected jobs are scarce in low-income countries. In Pôrto Alegre there is only one protected workshop with 25 places for a population with schizophrenia estimated at around 10000 people (Busnello et al, 1992). Many service users emphasised their feelings of uselessness, and merely providing low-level, supportive work opportunities or social security will not necessarily assuage this need, which is related to the person's role in the world. Self-stigmatising attitudes are often seen in marginalised groups and can be an important component of their sense of shame (Hayward \& Bright, 1997). The meaning of illness, loss of selfrespect and shame may be more important in determining health outcomes than any other aspect of human life (Marmot, 2003).

\section{Talking to patients}

People with schizophrenia may frequently wish to discuss their subjective experiences with their clinicians, but such themes are thought to be irrelevant (McCabe et al, 2002; Van Meer, 2003) or as surface manifestations of underlying neurological disturbance and of no interest in themselves. This limited approach disregards service users' existential distress and may prevent satisfactory relationships with their mental health professionals. What is traditionally seen by professionals to be the result of symptoms is seen by service users as an irreparable and painful loss of the capacity to 'be' and to live 'normally' in the world. An awareness by formal and informal carers of service users' perspectives may begin to diminish their anxiety and improve their self-image. Offering service usercentred skills, education, counselling or more structured forms of therapy such as cognitive-behavioural therapy will increase treatment compliance, improve satisfaction, decrease emotional distress and reduce symptoms (Morrison, 1998; Paley \& Shapiro, 2002). However, our data suggest that professionals' respect for and preparedness to listen to service users are prized over other needs.

\section{Need for meaning}

Expressions of emotional pain and a wish to die appeared constantly in the service users' transcripts. Why continue to live if there is little love, few goals to pursue, persistent feelings of stigma, a lack of professional fulfilment, dependence on others and rejection of one's own subjective experiences as worthy of respect? Satisfaction of the need for self-understanding, however, also depends on the individual's autonomy and personal capacity to fix goals and participate in social relationships. Some of the patients interviewed affirmed the importance of searching for information on the disease and of talking and reflecting about oneself and what has happened in one's life. Unfortunately, people with psychotic disorders may feel the need to be independent but do not consider themselves able to achieve it, and consequently suffer deeply (Wallace et $a l, 2000$ ).

\section{Meaning and outcome}

We might understand more about human motivation and adaptation in the face of personal crisis if we examined how people with schizophrenia find meaning in their lives. Social isolation and poverty of social relationships are associated with worse social and clinical prognosis for people with schizophrenia (Leff et al, 1992). Relapse is linked to high levels of expressed emotions by a family member, defined as critical, hostile or emotional over-involvement (Leff et al, 1990; Kavanagh, 1992; Wuerker et al, 2001). Most people with psychotic disorder report they are rejected and discriminated against both inside and outside the family (Crisp et al, 2000; Dinos et al, 2004). Meeting the needs for love, acceptance and avoidance of shame is one of the most important factors involved in the evolution of mental health disorders and their response to treatment (Tantum, 2002).

\section{Implications for care and research}

Too often, mental health professionals look upon their service users as less than fully human and do not listen to their stories. 
We need to give greater priority to existential issues in validated schedules that measure needs in clinical work and research. Finally, we intend to replicate this analysis in the data from all collaborating countries in this project. We expect to find the same core of existential needs, which by definition should not vary by culture to any significant degree.

\section{ACKNOWLEDGEMENTS}

We thank all the mental health service users and informal and formal carers who agreed to participate. Special thanks are also due to the Associacão Gaúcha de Familiares de Pessoas com Esquizofrenia and members of the Martistán network, in particular Ariadne Runte Geideil, Claudio Alberto Antoniolli, Maria-Ines Olivella and Francisco Torres. This study was conducted with the support and collaboration of the Department of Psychiatry of the Fundação Faculdade Federal de Ciencias Medicas de Pôrto Alegre and Camden and Islington Mental Health and Social Care Trust, London.

\section{REFERENCES}

Bauer, M. W. Gaskell, G. (2000) Qualitative Researching With Text, Image and Sound. London: Sage.

Brewin, C. R., Wing, J. K., Mangen, S. P., et al (1987) Principles and practice of measuring needs in the longterm mentally ill: the MRC Needs for Care Assessment. Psychological Medicine, I7, 97|-981.

Britten, N. (1995) Qualitative interviews in medical research. BMJ, 3II, 25I-253.

Brugha, T. S., Wing, J. K., Brewin, C. R., et al (1988) The problems of people in long-term psychiatric day care. Psychological Medicine, 18, 443-456.

Busnello, E. D., Pereira, M. O., Knapp, W. P., et al (1992) Morbidade psiquiátrica na população urbana de Porto Alegre. Jornal Brasileiro de Psiquiatria, 4I, 507-512.

Crisp, A. H., Gelder, M. G., Rix, S., et al (2000) Stigmatisation of people with mental illnesses. British Journal of Psychiatry, 177, 4-7.

Dinos, S., Stevens, S., Serfaty, M., et al (2004) Stigma: the feelings and experiences of 46 people with mental illness. Qualitative study. British Journal of Psychiatry, 184, 176-181.

Frankl, V. E. (1979) The Unheard Cry for Meaning: Psychotherapy and Humanism. London: Touchstone.

Gil-Garcia, E., Conti-Cuesta, F., Pinzón-Pulido S. A., et al (2002) El análisis de texto asistido por ordenador en la investigación cualitativa. Index de Enfermería, 36, 24-28.

Hayward, P. \& Bright, J. (1997) Stigma and mental illness: a review and critique. Journal of Mental Health, $\mathbf{6}$, 345-354.

Jablensky, A., Sartorius, N., Ernberg, G., et al (1992) Schizophrenia: Manifestations, Incidence and Course in Different Cultures. A World Health Organization TenCountry Study. Psychological Medicine. Monograph Supplement 20. Cambridge: Cambridge University Press.

\section{CLINICAL IMPLICATIONS}

Existential needs are crucial to service users and take precedence over more basic needs for housing and daily occupation.

- Existential needs cannot be ignored by clinicians or health service researchers.

- Needs assessment schedules should pay more attention to existential needs.

\section{LIMITATIONS}

- People with psychosis who were not in contact with health services were not included and as a consequence the sample was not necessarily representative of all patients with psychosis in Pôrto Alegre.

- Service users could not be included in the groups if they were unable to express themselves coherently.

- The findings arose from data collected in one country only.

LUCIANE C.WAGNER, MD, Hospital Psiquiátrico São Pedro and Faculty of Health Sciences, Rede Metodista de Educacão, Brazil; MICHAEL KING, MD, Royal Free and University College Medical School, London, UK

Correspondence: Professor Michael King, Royal Free and University College Medical School, Royal Free Campus, Rowland Hill Street, London NW3 2PF, UK. Tel: +44 (0)20 7830 2397; fax: +44(0)20 7830 2808; e-mail: m.king@medsch.ucl.ac.uk

(First received II November 2003, final revision 6 August 2004, accepted II August 2004)

Kavanagh, D. J. (1992) Recent development in expressed emotion and schizophrenia. British Journal of Psychiatry, 160, 60I-620.

Leff, J., Wig, N. N., Bedi, H., et al (1990) Relatives' expressed emotion and the course of schizophrenia in Chandigarh. A two-year follow-up of a first-contact sample. British Journal of Psychiatry, 156, 35I-356.

Leff, J., Sartorius, N., Jablensky, A., et al (1992) The International Pilot Study of Schizophrenia: five-year follow-up findings. Psychological Medicine, 22, |3|-145.

March Cerdà, J. C., Prieto Rodriguez, M. A., Hernán García, M., et al (1999) Técnicas cualitativas para la investigación en salud pública y gestión de servicios de salud: algo más que otro tipo de técnicas. Gaceta Sanitaria, 13, 312-319.

Marmot, M. (2003) Self esteem and health. BMJ, 327, 574-575.

Maslow, A. (1954) Motivation and Personality. New York Harper.

McCabe, R., Heath, C., Burns, T., et al (2002) Engagement of patients with psychosis in the consultation: conversation analytic study. BMJ, $\mathbf{3 2 5}$ ||48-|I5I.

Morrison, A. P. (1998) Cognitive behaviour therapy for psychotic symptoms in schizophrenia. In Treating Complex Cases: The Cognitive Behavioural Therapy Approach (eds

N. Tarrier, A. Wells \& G. Haddock), pp. 195-216.

Chichester: Wiley
Paley, G. \& Shapiro, D. A. (2002) Lessons from psychotherapy research for psychological interventions for people with schizophrenia. Psychology and Psychotherapy: Therapy, Research and Practice, 75, 5-17.

Phelan, M., Slade, M., Thornicroft, G., et al (1995) The Camberwell Assessment of Need: the validity and reliability of an instrument to assess the needs of people with severe mental illness. British Journal of Psychiatry, 167, 589-595.

Tantum, D. (2002) Psychotherapy and Counselling in Practice. A Narrative Framework. Cambridge: Cambridge University Press.

Van Meer, R. (2003) Engaging patients with psychosis in consultations (letter). BMJ, 326, 549 .

Wallace, C. J., Liberman, R. P., Tauber, R., et al (2000) The independent living skills survey: a comprehensive measure of the community functioning of severely and persistently mentally ill individuals. Schizophrenia Bulletin, 26, $631-658$.

World Health Organization (1973) Report of the International Pilot Study of Schizophrenia. Geneva: WHO.

World Health Organization (1992) The ICD-10

Classification of Mental and Behavioural Disorders. Geneva: WHO.

Wuerker, A. K., Haas, G. L. \& Bellack, A. S. (200I) Interpersonal control and expressed emotion in families of persons with schizophrenia: change over time. Schizophrenia Bulletin, 27, 67I-685. 